\title{
The Development of Flagella in Swarm Cells of the Myxomycete Physarum flavicomum
}

\author{
By H. C. ALDRICH \\ Department of Botany, University of Florida \\ Gainesville, Florida, U.S.A. $3260 \mathrm{I}$ \\ (Accepted for publication I4 July 1967) \\ SUMMARY
}

Myxamoebae of Physarum flavicomum and the stages of their development of flagella during transformation into biflagellate swarm cells were examined with the electron microscope. Fixation was with glutaraldehyde osmium. The flagellation process was similar to that reported in other systems, involving budding of the basal body into a primary flagellar vesicle which then forms the flagella sheath. Two basal bodies are present in the myxamoeba prior to flagellum development; other morphological features of myxamoebae and swarm cells, including systems of microtubules, are described. Mitochondria of both stages contain a dense core, flagella exhibit the typical ' 9 plus 2' arrangement, and the doublet fibrils of the axoneme become singlets near the rounded distal end of the flagellum.

\section{INTRODUCTION}

Swarm cells of myxomycetes have been studied with the light microscope by several workers (Lister, I9I I ; Cadman, I93 I ; von Stosch, I935; Elliott, I949; Kerr, I960) and appear uninucleate, elongated and in many cases biflagellate. An early study with the electron microscope (Cohen, 1959) yielded little new information, but a more recent investigation by Schuster (1965a) detailed subcellular structure of the myxamoebae, swarm cells, and stages in transformation of the former into the latter. Ultrastructural studies on other systems (Sotelo \& Trujillo-Cenoz, 1958 $a, b$; Sorokin, I962; Schuster, 1963; Renaud \& Swift, 1964; Dingle \& Fulton, 1966; Stubblefield \& Brinkley, 1966) have indicated at least two patterns of flagellum morphogenesis: (I) simple outgrowth of the axoneme at the cell surface (Dingle \& Fulton, I966); (2) development of a primary flagellar vesicle at the proximal end of the basal body, subsequent elongation of this vesicle with the growing axoneme, and ultimate fusion of this vesicle with the plasma membrane as the flagellum emerges (Sorokin, I962; Renaud \& Swift, I964; Stubblefield \& Brinkley, 1966). Other workers (Sotelo \& Trujillo-Cenoz, I958 $a, b$; Schuster, I963) have indicated sequences varying slightly from these basic patterns. The present study documents stages indicating that myxamoebae of Physarum flavicomum develop flagella as in pattern 2 above, contrasting with Schuster's report (Schuster, $1965 a$ ) that the process in Didymium nigripes, a related species, follows pattern I above.

I have recently shown (Aldrich, I967) that the basal bodies of the myxamoebae are present in the spores after meiosis is complete, confirming earlier observations made by von Stosch (1935) with the light microscope. Study of details of the amoeba- 
flagellate transformation in myxomycetes is considerably simplified by the fact that the transformation can be induced synchronously in a culture of amoebae by the addition of distilled water. Details of this system were described by Kerr (I960), who followed the transformation with the light microscope.

\section{METHODS}

Single spores of the heterothallic myxomycete Physarum flavicomum were sown on half-strength cornmeal agar, and clones arising from such isolates were maintained with bacteria by successive subculture techniques. Flagellum development in such clones was induced by adding distilled water to agar cultures; within $2 \mathrm{hr}$ essentially all cells were flagellated. Myxamoebae, various stages of cells developing flagella, and mature swarm cells were fixed in cold $\mathrm{I} \cdot 5 \%$ or $2.5 \%$ glutaraldehyde, buffered with Sorenson phosphate to $\mathrm{pH} 7 \cdot 5$. After washing and staining with cold $\mathrm{I} \%$ osmium tetroxide for $\mathrm{I} \mathrm{hr}$, cells were washed and embedded in agar to facilitate handling, dehydrated, and embedded in epoxy resin mixture II of Mollenhauer (1964). Some samples received no glutaraldehyde pre-treatment, but were fixed in cold I \% osmium tetroxide with $0.002 \mathrm{M}$-calcium added. Blocks were sectioned with diamond knives on Sorvall models MT-I and MT-2 and post-stained with $0.5 \%$ uranyl acetate followed by Reynolds lead citrate (Reynolds, 1963). Observations were made with RCA microscopes models EMU $3-\mathrm{D}$ and $3-\mathrm{F}$ and with a Siemens Elmiskop I.

\section{OBSERVATIONS}

Myxamoebae beginning the transformation process (Pl. I, fig. I) contain typical organelles, including dictyosomes, endoplasmic reticulum, nucleus and mitochondria. The nucleus is beaked in the region near the basal bodies and dictyosomes, the association of the latter organelles having been noted by Schuster (1965a) and interpreted as the centrosphere of Bernhard \& deHarven (I960). The nucleus contains a prominent nucleolus. Attached to the basal bodies is much of the accessory microtubular apparatus which will later be detailed in the swarm cell. Mitochondria contain the dense core reported by Schuster $(1965 b)$ to be DNA. Mitochondria at this stage assume various shapes, at times even including an electron-transparent vacuole. Food vacuoles contain bacteria being digested. Contractile vacuoles are also present, although not shown in Pl. I, fig. I. Several homogeneous globules probably represent a storage product.

After cultures are wet, basal bodies of transforming individuals develop a primary flagellar vesicle at their distal end (P1. 2, fig. 2), as in systems investigated by Sorokin (I962), Renaud \& Swift (I964) and Stubblefield \& Brinkley (1966). This vesicle seems to form by the fusion of several smaller vesicles. Plate 2 , figs. 3-5 show the flagellar bud elongating into this vesicle which adds membrane by fusion of secondary vesicles (P1. 2, fig. 4), and which forms the flagellar sheath just as in the other systems mentioned. Evidently, just before emergence of the flagella, the two buds are within a common vesicle ( $\mathrm{Pl}$. 2, fig. 5); the significance of the electron dense globules in fig. 5 is unclear. Although they appear similar to familiar lead citrate artifacts, such dense bodies are only seen near developing flagella, which suggests that they may represent more than artifacts. Plate 2, fig. 2, 3 both show primary vesicles associated with the basal body of the longer flagellum, recognizable by its distinctive basal apparatus 
represented by the row of dense granules along the side. Whether the developing second flagellum also has a primary vesicle is not known, but Pl. 2, fig. 5 indicates that the two flagellar buds emerge together.

Also noteworthy are the presence of satellites on budding basal bodies (Pl. 2, fig. 3) as noted by Sorokin (1962), and a discontinuity of the proximal end of the basal body (P1. 2, fig. 3 ; P1. 4, fig. II), to which is attached an array of microtubules through a dense connexion. The significance of the satellites and of the discontinuity is unknown.

The mature swarm cell is elongated, the cone-shaped anterior region containing the basal bodies, Golgi apparatus, and the flat-topped nucleus. Posterior to the nucleus are mitochondria, regions of rough endoplasmic reticulum, and food vacuoles. Contractile vacuoles of a typical protozoan type occupy the posterior portion, which is amoeboid in behaviour, the anterior end of the cell being apparently held into a fairly rigid cone by microtubules attached to the longer flagellum.

These microtubules are in two concentric diverging arrays, the outer being attached to the basal body through dense bands partially encircling it. This outer array of approximately 40 microtubules, shown in grazing section in $\mathrm{Pl}$. 4, fig. I2 and in crosssection in $\mathrm{Pl}$. 4, fig. 13 , runs posteriorly just under the plasma membrane and ends about the level of the posterior portion of the nucleus. An inner array attached to this same flagellum through a dense connexion (PI. 4, figs. II, $\mathrm{I}_{3}$ ) ends in the cytoplasm near the nuclear envelope.

The shorter flagellum, usually seen recurved close to the body of the swarm cell, has only a single parallel array of 6-8 microtubules attached, these running posteriorly just beneath the plasma membrane (Pl. 4, figs. I I, I3). The microtubules just described appear typical of those found in the cytoplasm of a variety of plant and animal cells, with an osmiophilic outer cylinder and an electron-transparent core. The model of the anterior end of the swarm cell, shown in Pl. 3, fig. 9, illustrates the arrangement of these tubules.

The flagella themselves show the typical 9 plus 2 arrangement of fibrils when sectioned transversely ( $\mathrm{Pl}$. 3, fig. 8), and appear blunt in longitudinal section (P1. 4, fig. 10). Near the tip, the outer doublets become singlets (Pl. 3, fig. 7), suggesting that the terminal structure is similar to that of cilia of Diplodinium ecaudatum (Roth \& Shigenaka, 1964) and gill cilia of mussels (Satir, 1965).

\section{DISCUSSION}

The type of flagellum development described here is similar to that first outlined by Sorokin (1962) in bird and mammal fibroblasts and smooth muscle cells, subsequently in Allomyces by Renaud \& Swift (I964), and now most recently in Chinese hamster fibroblasts by Stubblefield \& Brinkley (I966). Earlier workers (Sotelo \& Trujillo-Cenoz, I $958 a, b)$ reported that the basal body first contacts the plasma membrane, causing it to invaginate to form the ciliary sheath; however, no such invaginations or necessity for contact of basal body with plasma membrane were apparent in the present study.

Schuster (1965a) reported that flagella of two other species of myxomycetes develop simply by the outgrowth of the axoneme at the surface of the cell, much as shown by Dingle \& Fulton in Naegleria (1966). My own experience indicates that early developmental stages in the proper orientation are infrequently encountered, making reconstruction of the sequence difficult. I feel, however, that the sequence presently reported 
is the usual one for Physarum flavicomum. Kerr's (1960) observation that flagella of Didymium nigripes appear quite suddenly fits with a sequence involving initial axoneme development inside the cell in association with a primary vesicle, followed by emergence by fusion of this vesicle with the plasma membrane, as described herein. However, this does not preclude the possibility that some species might develop differently. This possibility gains credibility when considered in view of the facts that meiosis in myxomycetes may vary in position among different species (Aldrich, 1967), and that mitosis in haploid stages, according to Schuster (1965a), is of an astral type (terminology of Roth, I964), while the mitotic spindle in diploid stages is intranuclear (Schuster, 1964; Koevenig \& Jackson, 1966; Aldrich, 1967). Further details of these mechanisms will be dealt with in a later paper, but these anomalies serve to illustrate the non-uniformity of myxomycetes in several respects, and it may well be that flagellum development follows different patterns in different species.

The morphology of the myxamoebae and swarm cells as reported here agrees well with that reported earlier for Didymium nigripes (Schuster, 1965a). All mature swarm cells examined were biflagellate, with the second flagellum shorter and recurved near the body of the swarm cell. The shorter flagellum is inactive in locomotion of living cells viewed with phase contrast, which may explain difficulties of light microscopists in finding the second flagellum. (For review of controversy concerning number of flagella in myxomycetes see Alexopoulos, 1963.) The coincidence of inactivity of this shorter flagellum with its small complement of associated microtubules, compared with the extensive arrays associated with the longer, active flagellum, suggests that the microtubules anchor the flagellum into the cytoplasm and contribute to the observed inflexibility exhibited by the anterior end of the swarm cell in the living condition.

The results just discussed indicate that myxomycetes share ultrastructural characters with diverse groups of organisms, including the universal flagellum morphology and the mode of flagellum development typical of fungi and higher animals. Certain unique features of the group, including synchronous mitosis in the plasmodial state, different mechanisms of karyokinesis in haploid and diploid stages, and spectacular reversible streaming of the plasmodium, make myxomycetes potentially extremely useful subjects for future research.

Portions of this work were included in a dissertation submitted to the Graduate School, University of Texas, in partial fulfilment of the requirements for the Ph.D. degree. Support is gratefully acknowledged from the following sources: NIH Training Grant in Cell Biology 5TI-GM-789 to the University of Texas, NSF Grant GB-2738 to C. J. Alexopoulos, an American Cancer Society Institutional Grant to the University of Florida, and the Graduate School, University of Florida.

\section{REFERENCES}

ALDRICH, H. C. (1967). Ultrastructure of meiosis in three species of Physarum. Mycologia 59, I27. Alexopoulos, C. J. (I96i3). The myxomycetes. II. Bot. Rev. 29, I.

BernhARD, W. \& DEHAR.VEN, E. (1960). L'ultrastructure du centriole et d'autres éléments de l'appareil achromatique. 4th Int. Conf. Electron. Microsc., Berlin, 2, 217.

Cadman, E. (I93I). The life history and cytology of Didymium nigripes Fries. Trans. R. Soc. Edinb. 57, 93.

CoHen, A. (1959). An electron microscope study of flagellation in myxomycete swarm cells (abst.). 9th Int. Bot. Congr. 2, 77. 
Dingle, A. D. \& Fulton, C. (1966). Development of the flagellar apparatus of Naegleria. J. Cell. Biol. 3r, 43.

ElLiotT, E. W. (1949). The swarm cells of myxomycetes. Mycologia 4r, I4I.

KERR, N. S., (1960). Flagella formation by myxamoebae of the true slime mold Didymium nigripes. J. Protozool. 7, 103.

KoeveniG, J. L. \& JACKSON, R. C. (1966). Plasmodial mitoses and polyploidy in the myxomycete Physarum polycephalum. Mycologia 58, 662.

Lister, A. (19II). A Monograph of the Mycetozoa, and ed. Revised by G. Lister, pp. 6-8. London: Br. Mus. Nat. Hist.

Mollenhauer, H. H. (1964). Plastic embedding mixtures for use in electron microscopy. Stain. Technol. 39, III.

Renaud, F. \& SWIFT, H. (1964). The development of basal bodies and flagella in Allomyces arbusculus. J. Cell Biol. 23, 339.

REYNOLDS, E. S. (1963). The use of lead citrate at a high pH as an electron-opaque stain in electron microscopy. J. Cell. Biol. 17, 208.

Roth, L. E. (1964). Motile systems with continuous filaments. In Primitive Motile Systems in Cell Biology. Ed. by R. D. Allen and N. Kamiya, pp. 527-548. New York: Academic Press.

Roth, L. E. \& ShigenaKa, Y. (1964). The structure and formation of cilia and filaments in rumen protozoa. J. Cell Biol. $20,249$.

SATIR, P. (1965). Studies on cilia. II. Examination of the distal region of the ciliary shaft and the role of the filaments in motility. J. Cell Biol. 26, 805.

SCHUSTER, F. L. (1963). An electron microscope study of the amoeboflagellate Naegleria gruberi. I. The amoeboid and flagellate stages. J. Protozool. ro, 297.

SCHUSTER, F. L. (1964). Electron microscope observations on spore formation in the true slime mold Didymium nigripes. J. Protozool. Ir, 207.

SCHUSTER, F. L. (1965a). Ultrastructure and morphogenesis of solitary stages of true slime molds. Protistologica $\mathbf{1}, 49$.

SCHUSTER, F. L. (I965b). A DNA component in mitochondria of Didymium nigripes, a slime mold. Exp. Cell Res. 39, 329.

SoRokin, S. (1962). Centrioles and the formation of rudimentary cilia by fibroblasts and smooth muscle cells. J. Cell Biol. 15, 363 .

Sotelo, J. R. \& Truilllo-Cenoz, O. (1958a). Electron microscope study of the kinetic apparatus in animal sperm cells. Z. Zellforsch. mikrosk. Anat. 48, 565 .

Sotelo, J. R. \& Trujlllo-Cenoz, O. (1958b). Electron microscope study on the development of ciliary components of the neural epithelium of the chick embryo. Z. Zellforsch. mikrosk. Anat. 49, I.

Stosch, H. A. von (1935). Untersuchungen über die Entwicklungsgeschichte der Myxomyceten. Planta 23, 623.

Stubblefield, J. E. \& Brinkley, B. R. (1966). Cilia formation in Chinese hamster fibroblasts in vitro as a response to Colcemid treatment. J. Cell Biol. 30, 645 . 
EXPLANATION OF PLATES

SYMBOLS USED

I Basal body of long flagellum

2 Basal body of short flagellum

C Contractile vacuole

D Dense body

G Golgi apparatus

I Inner microtubular array

M Mitochondrion
$N$ Nucleus
O Outer microtubular array
P Parallel microtubular array
PM Plasma membrane
PV Primary flagellar vesicle
S Satellite
V Food vacuole

Plate I

Physarum flavicomum

Fig. 1. Myxamoeba before transformation into swarm cell. Three food vacuoles contain phagocytized bacteria. Nucleus is pear-shaped. Mitochondria show characteristic dense core. Centrosphere region at upper right contains Golgi apparatus and basal bodies. $\times 24,000$.

\section{Plate 2}

Fig. 2. Primary flagellar vesicle is evidently forming at arrow by fusion of several smaller vesicles. $\times 90,000$.

Fig. 3. Flagellar bud is elongating. Note discontinuity of basal body at arrow. $\times 90,000$.

Fig. 4. Secondary vesicle fusing with primary flagellar vesicle (arrow). $\times 86,000$.

Fig. 5. Both flagella at time of emergence. $\times 70,000$.

\section{Plate 3}

Fig. 6. Longitudinal section of whole swarm cell. $\times 12,000$.

Fig. 7. Cross-section of flagellum near tip. Nine outer fibres are single. Diameter is reduced (compare with fig. 8 , printed at same magnification). $\times 197,000$.

Fig. 8. Cross-section of flagellum. Arms are present on doublet fibres. $\times 197,000$.

Fig. 9. Model of anterior portion of swarm cell.

\section{Plate 4}

Fig. 10. Longitudinal section of tip of longer flagellum. $\times 66,000$.

Fig. I I. Anterior of swarm cell, long section. Note dense body attached to basal body and discontinuity of latter. Line marks plane of section in fig. $13 . \times 55,000$.

Fig. 12. Grazing section of anterior of swarm cell, showing outer diverging microtubular array attached to longer flagellum. $\times 53,000$.

Fig. 13. Anterior of swarm cell, cross section, showing all three arrays of microtubules. 


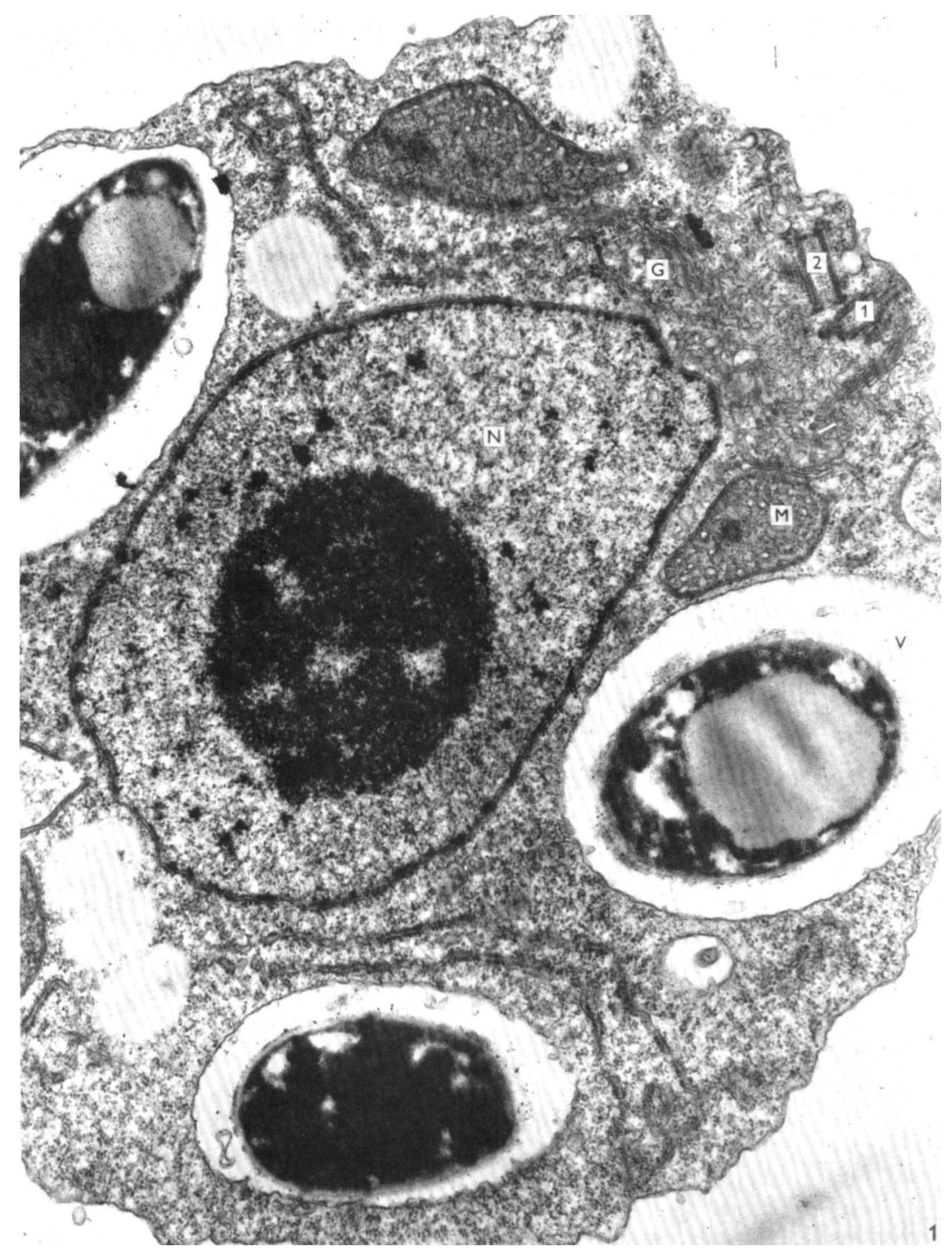




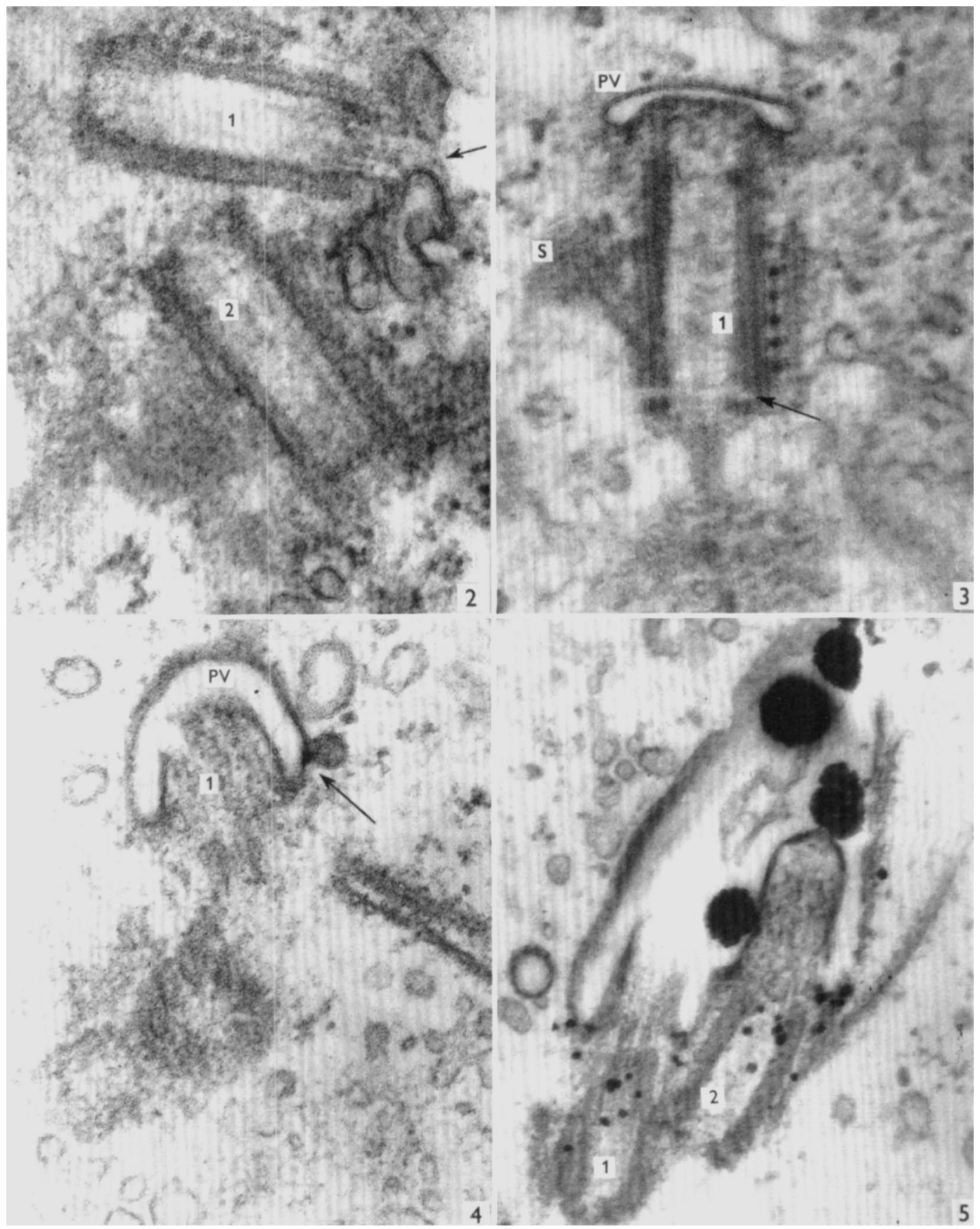

H. C. ALDRICH 
Journal of General Microbiology, Vol. 50, No. 2

Plate 3

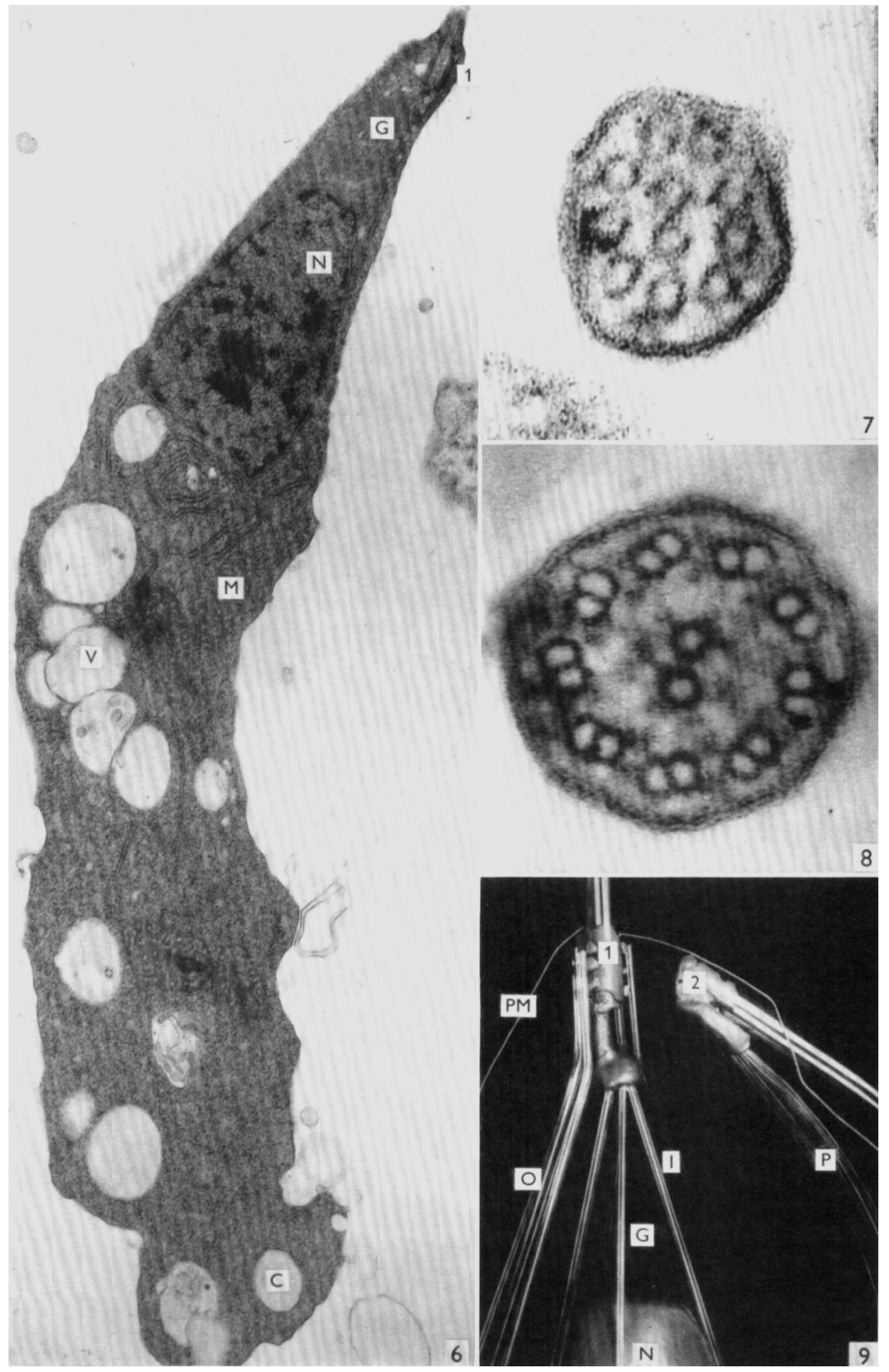

H. C. ALDRICH 


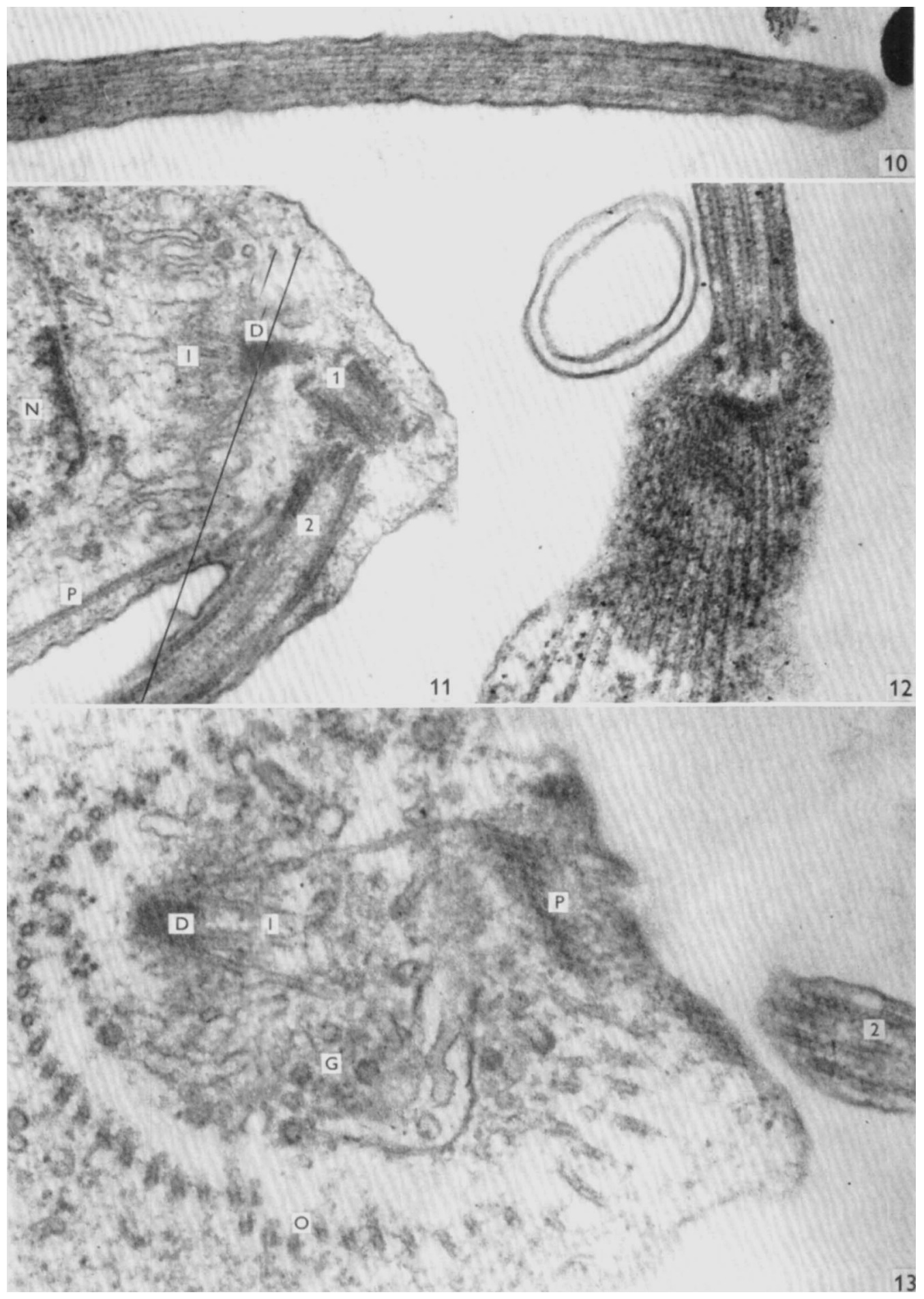

H. C. ALDRICH 